NASA Technical Memorandum 106653

\title{
Prediction of Film Cooling on Gas Turbine Airfoils
}

Vijay K. Garg and Raymond E. Gaugler

Lewis Research Center

Cleveland, Ohio

(NASA-TM-106653) PREDICTION OF

FILM COOLING ON GAS TURBINE

AIRFOILS (NASA. Lewis Research

Center) $31 \mathrm{p}$
M-ON

\section{310}




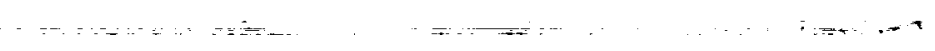




\title{
PREDICTION OF FILM COOLING ON GAS TURBINE AIRFOILS
}

\author{
Vijay K. Garg and Raymond E. Gaugler \\ Turbomachinery Flow Physics Branch \\ Internal Fluid Mechanics Division \\ NASA Lewis Research Center \\ Mail Stop 5-11 \\ Cleveland, OH 44135, USA
}

\section{ABSTRACT}

A three-dimensional Navier-Stokes analysis tool has been developed in order to study the effect of film cooling on the flow and heat transfer characteristics of actual turbine airfoils. An existing code (Arnone et al., 1991) has been modified for the purpose. The code is an explicit, multigrid, cell-centered, finite volume code with an algebraic turbulence model. Eigenvalue scaled artificial dissipation and variable-coefficient implicit residual smoothing are used with a full-multigrid technique. Moreover, Mayle's transition criterion (Mayle, 1991) is used. The effects of film cooling have been incorporated into the code in the form of appropriate boundary conditions at the hole locations on the airfoil surface. Each hole exit is represented by several control volumes, thus providing an ability to study the effect of hole shape on the film-cooling characteristics. Comparison is fair with near mid-span experimental data for four and nine rows of cooling holes, five on the shower head, and two rows each on the pressure and suction surfaces. The computations, however, show a strong spanwise variation of the heat transfer coefficient on the airfoil surface, specially with shower-head cooling. 


\section{NOMENCLATURE}

$B_{p}$ blowing parameter $\left[=\left(\rho_{c} V_{c} \gamma^{1 / 2}\right) /\left(\rho_{o} c_{o}\right)\right]$

$B_{r}$ blowing ratio $\left[=\left(\rho_{c} V_{c}\right) /\left(\rho_{\infty} V_{\infty}\right)\right]$

c sonic speed

d coolant hole diameter

$h$ heat transfer coefficient based on $\left(T_{0}-T_{w}\right)$

$h_{0}$ standard value $\left(=1135.6 \mathrm{~W} / \mathrm{m}^{2}-\mathrm{K}=200 \mathrm{Btu} / \mathrm{hr}^{-} \mathrm{ft}^{2}-\mathrm{R}\right)$

M Mach number

p pressure

r coolant hole radius $(=d / 2)$

Re Reynolds number based on the true chord length

s distance from the leading edge along the pressure or suction surface

$T$ temperature

$V_{c}$ average velocity of coolant at the hole exit

V. local free-stream velocity

$\mathrm{y}^{+}$dimensionless distance of the first point off the airfoil surface

$\gamma$ ratio of specific heats

p density

F curvilinear coordinate roughly following the flow

$\eta$ curvilinear coordinate running airfoil-to-airfoil

$\zeta$ cunvilinear coordinate running spanwise

\section{Subscripts}

1 at inlet

2 at exit 
c for coolant

- stagnation value

w at the airfoil surface

$\infty$ local free-stream value

\section{INIRODUCTION}

There is a growing tendency these days to use higher and higher temperatures at the inlet to a turbine since it yields higher thermal efficiency. Modern gas turbine engines are designed to operate at inlet temperatures of $1400-1500^{\circ} \mathrm{C}$, which are far beyond the allowable metal temperatures. Thus, to maintain acceptable life and safety standards, the structural elements need to be protected against the severe thermal loads. This calls for an efficient cooling system. One such cooling technique currently used for high temperature turbines is film cooling. In this technique, cooler air is injected into the high temperature boundary layer on the airfoil surface. Since the cooler air is bled directly from the compressor before it passes through the combustion chamber, it represents a loss in the total power output. The designer's goal is therefore to minimize the coolant necessary to insure adequate turbine life.

To this end, considerable effort has been devoted into understanding the coolant film behavior and its interaction with the mainstream flow. The film cooling performance is influenced by the wall curvature, three-dimensional external flow structure, free-stream turbulence, compressibility, flow unsteadiness, the hole size, shape and location, and the angle of injection. Many studies on film cooling have been confined to simple geometries, for example, two-dimensional flat and curved plates in steady, incompressible flow. A survey of work up to 1971 has been provided by Goldstein (1971). While several further 
studies in this field have been summarized by Garg and Gaugler (1993), some recent ones are discussed here. Metzger et al. (1993) provide a descriptive overview of turbine cooling methods and situations of current interest. They point out the relative invariance of some of the problems addressed during the development of the gas turbine engine over the past five decades. Moreover, they note that while a large information base has been accumulated on film cooling, the designer's ability to predict film cooling performance in general is still marginal.

Vogel (1991) described a 3-D Navier-Stokes code for film-cooled gas turbine blades that couples the flow problem over the blade with the 3-D heat conduction problem within the blade. Using the Baldwin-Lomax mixing length model (Baldwin and Lomax, 1978) coupled with the Cebeci-Smith near-wall damping model (Cebeci and Smith, 1974), Vogel compared the heat transfer coefficients with experimental data for injection on a flat plate. He could not get reliable results on a turbine blade due to the computer storage limitations that did not allow more than four to six mesh cells within the hole opening on the blade surface. Vogel found, in conformity with our observation as well, that more than six cells within the hole are required for an adequate resolution of the flow field.

Benz and Wittig (1992) analyzed the elliptic interaction of film-cooling air with the main flow by simultaneously computing the coolant and main flows for film cooling at the leading edge of a turbine blade. They were, however, concerned with the region surrounding the hole, and presented no heat transfer results. Amer et al. (1992) compared two forms each of the $k-\epsilon$ and $k-\omega$ family of turbulence models for film cooling, and found all of them to be inappropriate. Recently Domey and Davis (1993) analyzed the film cooling effectiveness from one and two rows of holes on a turbine vane, using Rai's (1989) numerical technique. They carried out both two- and three-dimensional 
simulations, but represented each hole by just two grid points. Choi (1993) developed a multi-zone code for film cooling with a fine mesh near the coolant hole and injection pipe overlapped on the global coarse grid. Using modified Coakley's q- $\omega$ turbulence model, he found reasonable agreement with the film-cooled ACE blade. However, only one row of holes on the suction surface of the blade was analyzed.

More recently, Leylek and Zerkle (1993) analyzed the coupled problem of flow in the plenum, film-hole, and cross-stream region for film-cooling on a flat plate using the $k-\epsilon$ model of turbulence in a 3-D Navier-Stokes code. They found the flow within the film-hole to be extremely complex, containing counter-rotating vortices and local jetting effects that make the flow field in this region highly elliptic. The distribution of dependent variables at the hole exit plane resulted from the interaction of three competing mechanisms, namely, counter-rotating structure and local jetting effects within the film-hole, and crossflow blockage. They found that for the high hole-length to diameter ratios $(\geq 3.0)$, the velocity profile at the hole exit is akin to the $1 / 7$ th power-law profile for high blowing ratios $\left(B_{r} \geq 1.0\right)$.

Herein, an existing three-dimensional Navier-Stokes code (Arnone et al., 1991) has been modified in order to study the effect of film cooling on the flow and heat transfer characteristics of actual turbine airfoils. Comparison with experimental data (Hylton et al., 1988) for a C3X vane with four as well as nine rows of film cooling holes including the shower-head is provided.

\section{ANALYSIS}

The three-dimensional Navier-Stokes code of Amone et al. (1991) for the analysis of turbomachinery flows was modified to include film cooling effects and Mayle's transition 
criterion (Mayle, 1991). The code is an explicit, multigrid, cell-centered, finite volume code with an algebraic turbulence model. The Navier-Stokes equations in a rotating Cartesian coordinate system are mapped onto a general body-fitted $(\xi, \eta, \zeta)$ coordinate system using standard techniques, with the $\xi$-coordinate roughly following the flow, the $\eta$-coordinate running airfoil-to-airfoil, and the $\zeta$-coordinate running spanwise. Viscous effects in the $\xi$ direction are neglected in comparison to those in the $\eta$ and $\zeta$-directions. This assumption is not good for high blowing ratios. However, inclusion of viscous effects in the $\xi$ direction requires a fairly dense grid in the $\xi$-direction as well. Since the present code is a one-domain (though multi-grid) code, it is not practical to include viscous effects in the $\xi$-direction also. This assumption may affect the results in the vicinity of film cooling holes. Since the experimental data on the C3X vane is available away from the holes, this assumption may not affect the comparison with experimental data to a large extent.

The number of grid points specified on the pressure and suction surfaces of the airfoil are different, thus producing a non-matching grid on the "cut-line" in the wake region. Though it requires interpolation, it allows the grid to be only slightly distorted even for cascades having a large camber or a high stagger angle, and for airfoils with several rows of film-cooling holes, thus enabling one to describe details of the flow with a reasonable number of grid points. The four-stage Runge-Kutta scheme developed by Jameson et al. (1981) is used to advance the flow solution in time from an initial guess to the steady state. A spatially varying time step along with a CFL number of 5 was used to speed convergence to the steady state. Eigenvalue-scaled artificial dissipation and variable-coefficient implicit residual smoothing are used along with a fult-multigrid method.

The effects of film cooling have been incorporated into the code in the form of appropriate boundary conditions at the hole locations on the airfoil surface. Each hole 
exit (generally an ellipse in the plane of the airfoil surface) is represented by several control volumes (about 20 ) having a total area equal to the area of the hole exit, and passing the same coolant mass flow. This provides the code an ability to study the effect of hole shape on the film-cooling characteristics, though such an effect is not demonstrated here. Different velocity and temperature profiles for the injected gas can be specified at the hole exit. For the cases reported here, turbulent (1/7th power-law) profiles were specified, in conformity with the observation of Leylek and Zerkle (1993), since the hole-length to diameter ratio for the $\mathrm{C} 3 \mathrm{X}$ vane is 3.4 . The code can also be used for either a specified heat flux or a variable temperature condition on the airfoil surface. For the C $3 X$ vane analyzed here, the experimentally determined temperatures were specified at the airfoil surface, and wall heat flux was calculated. The algebraic mixing length turbulence model of Baldwin and Lomax (1978) was used. This model has been used satisfactorily by Boyle and Giel (1992) for heat transfer calculations on turbine blades without film cooling. Moreover, Mayle's transition criterion (Mayle, 1991) was employed. The incoming flow in the experimental tests on C3X vane (Hytton et al., 1988) had a turbulence intensity of $6.5 \%$, and it is assumed constant for application of Mayle's model.

Since the hole diameter on the C $3 X$ vane is $0.99 \mathrm{~mm}$, the grid size has to be varied along the airfoil chord. For computational accuracy, the ratio of two adjacent grid sizes in any direction was kept within 0.76 to 1.3 . A periodic $C$-grid with up to one million grid points was used. Normal to the airfoil surface is the dense viscous grid, with $y^{+}<1$ for the first point off the airfoil surface, following Boyle and Giel (1992). Computations were run on the 8-processor Cray Y-MP supercomputer at the NASA Lewis Research Center, and on the 16-processor C-90 supercomputer at NASA Ames Research Center. The 
code requires about 60 million words $(\mathrm{Mw})$ of storage and takes about $20 \mathrm{~s}$ per iteration (full-multigrid) on the C-90 machine for one million grid points. For a given grid the first case requires about 1100 iterations to converge, while subsequent cases for the same grid require about 300 iterations starting with the solution for the previous case.

\section{EXPERIMENTAL DETAILS}

The code was assessed against the experimental data on the C $3 X$ vane in a linear cascade by Hylton et al. (1988). Figure 1 shows the C3X vane (true chord $=144.93 \mathrm{~mm}$ ) with the film cooling hole details. The test vane was internally cooled by an array of ten radial cooling holes (not shown in Fig. 1) in the active part of the vane. No heat transfer measurements were made in the actual film-cooled nose piece of the vane as it was thermally isolated from the rest of the vane. The active part of the test vane surface was instrumented with $1230.51 \mathrm{~mm}$ diameter sheathed CA thermocouples to measure the temperature at the airfoil surface. The thermocouple junctions were located in a plane $2.54 \mathrm{~mm}$ off mid-span. The heat transfer coefficient for each radial cooling hole was calculated from the hole diameter, measured coolant flow rate, and coolant temperature with a correction applied for thermal entry region effects. The internal temperature field of the test vane was obtained from a finite element solution of the steady state heat conduction equation, using the measured surface temperatures as boundary conditions. Experimental values of the heat flux at the airfoil surface were then obtained from the normal temperature gradient at the airfoil surface, and these were used to derive the local heat transfer coefficient, represent values in a plane $2.54 \mathrm{~mm}$ off the mid-span of the airfoil. More details are available in Hylton et al. (1988). 


\section{RESULTS AND DISCUSSION}

Fig. 2 shows the $281 \times 45$ grid in the $\xi-\eta$ directions around the C $3 X$ vane with all the nine rows of holes. The concentration of grid lines in regions near the holes on the leading edge and on pressure and suction surfaces can be noticed in this figure. Also visible is the non-matching grid structure on the "cut-line" in the wake region, resulting from the different number of grid points on the suction and pressure surfaces of the airfoil. This helps reduce grid skewness, specially over the suction surface of the airfoil. The same grid is stacked in the $\zeta$-direction along the span.

Comparisons were made with the experimental data for (i) all the nine rows of filmcooling holes (five rows of staggered holes in the shower-head around the stagnation point and two rows each of in-line holes on the pressure and suction surfaces), and (ii) four rows of cooling holes with the shower-head blocked. For both these cases, the computational span, shown in Fig. 3 , is different from the real span. The ordinate in Fig. 3 denotes the distance along the airfoil surface in the spanwise direction, while the abscissa denotes the distance along the airfoil surface in the chordwise direction, both normalized by the hole radius, $r$. It may be noted that the abscissa in Fig. 3 has breaks so as to accommodate all the rows of holes. The shape and orientation of the hole openings in Fig. 3 is a direct consequence of the angles the holes make with the sparwwise or chordwise direction (cf. Fig 1). For case (i) with nine rows of holes, the pattem of holes shown in Fig. 3 is repeated in the spanwise direction, and since injection from the shower-head holes is at an angle of $45^{\circ}$ with the span direction, periodic boundary conditions are imposed on the ends of the computational span. For case (ii), however, with the shower-head holes blocked, injection from the rows of holes being normal to the surface in the spanwise direction allows symmetry boundary conditions to 
be imposed at both ends of the computational span.

Three experimental cases, 44103, 44108 and 44308, were analyzed for comparison when the shower-head holes are blocked, and three experimental cases, 44135, 44155 and 44355, were analyzed for comparison with all nine rows of holes injecting the cold gas. The values of various parameters for these cases are given in Table 1. In this table, the derived film cooling parameters are based upon the assumption of one-dimensional compressible flow through the hole. With the shower-head holes blocked, the case 44108 represents the maximum while the case 44103 represents the minimum coolant mass flow rate for the experimental data. In terms of the coolant temperature, the case 44108 represents the coolest while the case 44308 represents the warmest coolant when the shower-head holes are blocked. With all nine rows of holes on, the cases 44135 and 44155 represent the minimum and maximum blowing ratio, respectively, for the showerhead holes, while the case 44355 represents the warmest coolant. In all cases, the blowing ratio is high $\left(B_{r} \geq 1.0\right)$.

Figure 4 shows the non-uniform experimentally determined temperature on the airfoil surface for the case 44308 , and is typical of all the cases analyzed. These temperature values were specified as the boundary condition for the airfoil surface temperature in the code as well. In this and later figures, s represents the normalized distance along the pressure or suction surface of the airfoil. Besides the somewhat erratic temperature variation over $|s|>0.25$, caused by the internal cooling holes (not shown in Fig. 1) in the active part of the airfoil, there is a sharp drop in temperature at each end of the insulated portion of the airfoil $(|s| \approx 0.25)$.

Figures 5 and 6 show a comparison of the static pressure distribution (solid curve) on the airfoil surface for the cases 44155 (with all nine rows of holes on) and 44108 (with 
the shower-head blocked), respectively, with the experimental data (denoted by $\square$ ) for the uncooled airfoil. The comparison is fairly good, and in conformity with Hylton et al. (1988), film-cooling does not seem to affect the static pressure distribution except producing some wiggles in the injection regions. It may be noted that for all the six experimental cases analyzed here, the pressure distribution is almost identical, and all grids yield the same result. Figure 7 shows the distribution of $y^{+}$for the first point off the airfoil surface for the case 44155 . The wiggles in the curve near $|s| \leq 0.25$ are due to the coolant injection. Clearly $y^{+}<1$ over the whole airfoil surface, as required for accurate heat transfer calculations (Boyle and Giel, 1992). Similar values of $y^{+}$were obtained for the other cases as well.

Figure $8(a)$ displays the heat transfer coefficient contours on the airfoil surface for the case 44155 along the normalized chordwise (abscissa) and spanwise (ordinate) directions. It may be noted that while the ordinate in this figure represents only about 15 $\mathrm{mm}$ of computational span, the abscissa represents about $320 \mathrm{~mm}$ of the airfoil surface in chordwise direction. The heat transfer coefficient values have been normalized by $h_{0}$ $=1135.6 \mathrm{~W} / \mathrm{m}^{2}-\mathrm{K}$, an arbitrary value used by Hylton et al. (1988). The contours are given at intervals of 0.2 in $h / h_{0}$ values. Clearly, the heat transfer coefficient has a strong three-dimensional structure over most of the airfoil surface, with relatively low values directly downstream of the holes on the suction surface. For the sake of clarity, the contours on the suction and pressure surfaces are blown up in Figs. $8(\mathrm{~b})$ and $8(\mathrm{c})$, respectively, for $|s|>0.3$, and the contours are given at intervals of $0.1 \mathrm{in} h / h_{0}$ values. It may be noted from Fig. $8(\mathrm{~b})$ that over $0.3 \leq \mathrm{s} \leq 0.5, \mathrm{~h} / \mathrm{h}_{\mathrm{o}}$ values range from 0.6 to 2.0 in regions of the span upstream of which there are no holes on the suction surface. Fig. 8 (b) also shows a slight tilt (an angle of about $5^{\circ}$ with the s-direction) of the $h / h_{0}$ contours 
in the region $0.3 \leq s \leq 0.5$. This is due to the relatively strong spanwise injection $\left(B_{p}=\right.$ 0.41) of the coolant through the shower-head holes (cf. Table 1) for this case. For the weaker blowing parameter $\left(B_{p}=0.2\right)$ through the shower-head holes for the case 44135 , Fig. 9 shows no such tilt of the $h / h_{0}$ contours (given at intervals of 0.1 ) on the suction surface. In fact, results in Fig. 9 appear to be almost symmetrical about the midcomputational span $(\zeta=0.5)$, even though the strong three-dimensional structure of the heat transfer coefficient is maintained. It may be noted that injection from the showerhead holes is at $45^{\circ}$ to the span direction and normal to the chordwise direction.

Figure 10 provides a comparison of the normalized heat transfer coefficient (solid curves) at the airfoil surface with experimental data (Hylton et al., 1988), denoted by $\square$, for the case 44155 at a spanwise location (near mid-span) where the experimental data was taken. There is no data given for about $25 \%$ of surface length on either side of the leading edge since this portion contained the plenum chambers for injection of the colder gas and was insulated from the rest of the airfoil in the experimental tests (cf. Fig. 1). Due to lack of experimental data on the mean temperature of the injected gas at the hole exit, it was necessary to estimate it based on a one-dimensional compressible flow through the hole. Despite this estimate, the comparison between the computed and experimental heat transfer coefficients is fair. The fluctuations in the data are due to the non-uniform airfoil surface temperature in the experimental data. It may be pointed out that when the iterative procedure for solution of the governing equations is assumed to converge, the maximum error in any of the variables is of the order of $10^{-4}$. Further iterations produced negligible change in the heat transfer coefficient.

Figures 11 and 12 provide a comparison between the present computations (solid curves) and experimental data (denoted by $\square$ ) for the normalized heat transfer coefficient 
for the cases 44135 and 44355 , respectively. In general, the agreement is fair. Though at a somewhat different level quantitatively, the theory seems to follow the fluctuations in the data, which are again due to the non-uniform airfoil surface temperature, similar to those in Fig. 4 for the case 44308 . We may point out that experimentally, the heat flux on the airfoil (inner) surface was calculated from a finite element analysis of conduction within the airfoil, and the heat transfer coefficient was then found by dividing this heat flux by $\left(T_{0}-T_{w}\right)$. The present study computes the heat transfer coefficients on the airfoil (outer) surface from the three-dimensional Navier-Stokes analysis. Also, the uncertainty in the heat transfer coefficient measurement varies from about $10 \%$ near $|s| \approx 0.3$ to about $22 \%$ near $|s| \approx 0.95$ (Hyltcn et al., 1988).

Let us now turn to the comparison of results for only the four rows of holes on the pressure and suction surfaces, with the shower-head holes blocked. Figure 13(a) shows the $h / h_{0}$ contours on the airfoil surface (at intervals of 0.1 ) for the case 44103 , and is the counterpart of Fig. 8(a) for all nine rows of holes on. The stretching in Fig. 13(a) is even more severe since the ordinate represents only about $3 \mathrm{~mm}$ of the computational span, while the abscissa represents about $320 \mathrm{~mm}$ of the chordwise distance on the airfoil surface. The computational span contains only one hole in each row with symmetry conditions at both the ends. In this case also, the three-dimensional nature of heat transfer coefficient is evident but only over $0.3 \leq|s| \leq 0.5$, not the entire $s$ as in Fig. $8(a)$.

Figures $13(b)$ and $13(c)$ provide the blow-up for these contours on the suction and pressure surfaces, respectively, for $|s|>0.3$ at intervals of 0.1 in $h / h_{0}$ values. Similar results were obtained for cases 44108 and 44308.

For the cases 44103,44108 and 44308 , respectively, Figs. 14 through 16 compare the theoretical heat transfer coefficient at the airfoil. surface (solid curves) with the 
experimental values (Hylton et al., 1988), denoted by $\square$, at the mid-computational span, close to the location of actual measurement. The comparison is fair on the pressure surface but not so on the suction surface. A possible cause for this discrepancy may be the use of an algebraic turbulence model for the analysis. It is known (Amer et al., 1992), however, that more sophisticated turbulence models, such as the two-equation models, are also not satisfactory in the presence of film cooling. Perhaps the multiple-time-scale turbulence model of Kim and Benson (1992) may be more appropriate. However, use of this model is computationally very expensive since it involves solving four more partial differential equations in addition to the five at present, all coupled.

Figure 17 shows the small effect of using Mayle's transition criterion for the case 44103. In this figure, the computed heat transfer coefficients with and without Mayle's model are shown at $1 / 6$ th of the computational span. Similar results were obtained at other span locations, and for the cases 44108 and 44308 . Since the flow turns turbulent right at the leading edge when shower-head cooling is on, Mayle's transition criterion makes no difference in results for the cases with all nine rows of cooling holes on.

\section{CONCLUSIONS}

A fair comparison of numerical results with near mid-span experimental data suggests that the multi-grid code can be used to predict the heat transfer characteristics of a film-cooled turbine airfoil with several rows of holes injecting through the shower-head and pressure and suction surfaces. It does show a strong spanwise variation of the heat transfer coefficient on the airfoil surface, specially with shower-head cooling. However, a complete comparison of this three-dimensional structure of the heat transfer coefficient

on the airfoil surface can not be done at present due to the lack of similar experimental 
data. It is planned to use the code to study the effect of various film-cooling parameters such as the hole size, shape and location, the angle of injection, etc.

\section{ACKNOWLEDGEMENTS}

This work was done when the first author held a National Research Council - NASA Research Associateship at the NASA Lewis Research Center. Helpful discussions with A.A. Ameri and R.J. Boyle of the NASA Lewis Research Center, and useful comments of the reviewers are gratefully acknowledged. 


\section{REFERENCES}

Amer, A.A., Jubran, B.A. and Hamdan, M.A., 1992, "Comparison of Different TwoEquation Turbulence Models for Prediction of Film Cooling from Two Rows of Holes," Numer. Heat Transfer, Vol. 21, Part A, pp. 143-162.

Arnone, A., Liou, M.-S. and Povinelli, L.A., 1991, "Multigrid Calculation of ThreeDimensional Viscous Cascade Flows," AlAA Paper 91-3238.

Baldwin, B.S. and Lomax, H., 1978, "Thin-Layer Approximation and Algebraic Model for Separated Turbulent Flows," AIAA Paper 78-257.

Benz, E. and Wittig, S., 1992, "Prediction of the Interaction of Coolant Ejection with the Main Stream at the Leading Edge of a Turbine Blade: Attached Grid Application," Proc. Intl. Symp. Heat Transfer in Turbomachinery, Athens, Greece.

Boyle, R.J. and Giel, P., 1992, Three-Dimensional Navier Stokes Heat Transfer Predictions for Turbine Blade Rows," AlAA Paper 92-3068.

Cebeci, T. and Smith, A.M.O., 1974, "Analysis of Turbulent Boundary Layers," Academic Press, New York.

Choi, D., 1993, "A Navier-Stokes Analysis of Film Cooling in a Turbine Blade," AIAA Paper 93-0158.

Dorney, D.J. and Davis, R.L., 1993, "Numerical Simulation of Turbine Hot Spot Alleviation Using Film Cooling," J. Propul. Power, Vol. 9, pp. 329-336.

Garg, V.K. and Gaugler, R.E., 1993, "Heat Transfer in Film-Cooled Turbine Blades," ASME Paper 93-GT-81.

Goldstein, R.J., 1971, "Film Cooling," Advances in Heat Transfer, Vol. 7, pp. 321-379.

Hylton, L.D., Nirmalan, V., Sultanian, B.K. and Kaufman, R.M., 1988, The Effects of Leading Edge and Downstream Film Cooling on Turbine Vane Heat Transfer," NASA CR 
182133.

Jameson, A., Schmidt, W. and Turkel, E., 1981, "Numerical Solutions of the Euler Equations by Finite Volume Methods Using Runge-Kutta Time-Stepping Schemes," AIAA Paper 81-1259.

Kim, S.-W. and Benson, T.J., 1992, "Calculation of a Circular Jet in Cross Flow with a Multiple-Time-Scale Turbulence Model," Intl. J. Heat Mass Transfer, Vol. 35, pp. 23572365.

Leylek, J.H. and Zerkle, R.D., 1993, "Discrete-Jet Film Cooling: A Comparison of Computational Results with Experiments," ASME Paper 93-GT-207.

Mayle, R.E., 1991, The Role of Laminar-Turbulent Transition in Gas Turbine Engines," J. Turbomachinery, Vol. 113, pp. 509-537.

Metzger, D.E., Kim, Y.W. and Yu, Y., 1993, Turbine Cooling: An Overview and Some Focus Topics," Proc. 6th Intern. Symp. Transport Phenomena in Thermal Engineering, Seoul, Korea.

Rai, M.M., 1989, "Three-Dimensional Navier-Stokes Simulations of Turbine RotorStator Interaction; Part I - Methodology," AIAA J. Propul. \& Power, Vol. 5, pp. 305-311.

Vogel, T., 1991, "Computation of 3-D Viscous Flow and Heat Transfer for the Application to Film Cooled Gas Turbine Blades," Paper 7, AGARD-CP-510. 
TABLE 1 Parameter Values for the Cases Analyzed

Main Flow Parameters (Experimental)

\begin{tabular}{|c|c|c|c|c|c|c|}
\hline Case & $p_{0}\left(\mathrm{kN} / \mathrm{m}^{2}\right)$ & $\mathrm{T}_{0}(\mathrm{~K})$ & $\mathrm{M}_{1}$ & $\mathrm{Re}_{1}$ & $\mathrm{M}_{2}$ & $\mathrm{Re}_{2}$ \\
\hline 44103 & 279.1 & 709 & 0.18 & $5.5 \times 10^{5}$ & 0.89 & $1.96 \times 10^{6}$ \\
\hline 44108 & 281.9 & 703 & 0.20 & $6.3 \times 10^{5}$ & 0.89 & $2.0 \times 10^{6}$ \\
\hline 44308 & 283.9 & 711 & 0.21 & $6.4 \times 10^{5}$ & 0.89 & $1.98 \times 10^{6}$ \\
\hline 44135 & 281.55 & 705 & 0.20 & $6.2 \times 10^{5}$ & 0.90 & $2.0 \times 10^{6}$ \\
\hline 44155 & 280.95 & 705 & 0.19 & $6.0 \times 10^{5}$ & 0.90 & $2.0 \times 10^{6}$ \\
\hline 44355 & 284.02 & 702 & 0.18 & $5.6 \times 10^{5}$ & 0.90 & $2.02 \times 10^{6}$ \\
\hline
\end{tabular}

Film Cooling Parameters (Experimental)

\begin{tabular}{|c|c|c|c|c|c|c|}
\hline Case & \multicolumn{3}{|c|}{$P_{o d} / P_{0}$} & \multicolumn{3}{c|}{$T_{o d} / T_{0}$} \\
\cline { 2 - 7 } & $\begin{array}{c}\text { Shower } \\
\text { Head }\end{array}$ & $\begin{array}{c}\text { Suction } \\
\text { Surf. }\end{array}$ & $\begin{array}{c}\text { Pressure } \\
\text { Surf. }\end{array}$ & $\begin{array}{c}\text { Shower } \\
\text { Head }\end{array}$ & $\begin{array}{c}\text { Suction } \\
\text { Surf. }\end{array}$ & $\begin{array}{c}\text { Pressure } \\
\text { Surf. }\end{array}$ \\
\hline 44103 & 1.000 & 1.020 & 1.019 & 1.00 & 0.68 & 0.72 \\
\hline 44108 & 1.000 & 1.635 & 1.692 & 1.00 & 0.63 & 0.66 \\
\hline 44308 & 1.000 & 1.614 & 1.636 & 1.00 & 0.85 & 0.85 \\
\hline 44135 & 1.018 & 1.099 & 1.099 & 0.75 & 0.67 & 0.69 \\
\hline 44155 & 1.103 & 1.101 & 1.101 & 0.72 & 0.66 & 0.69 \\
\hline 44355 & 1.099 & 1.101 & 1.102 & 0.85 & 0.84 & 0.83 \\
\hline \hline
\end{tabular}

\section{Film Cooling Parameters (Derived)}

\begin{tabular}{|c|c|c|c|c|c|c|}
\hline Case & \multicolumn{3}{|c|}{$\left(\rho_{c} \mathrm{~V}_{c} \gamma^{1 / 2}\right) /\left(\rho_{0} c_{0}\right)$} & \multicolumn{4}{c|}{$T_{d} / T_{0}$} \\
\cline { 2 - 8 } & $\begin{array}{c}\text { Shower } \\
\text { Head }\end{array}$ & $\begin{array}{c}\text { Suction } \\
\text { Surf. }\end{array}$ & $\begin{array}{c}\text { Pressure } \\
\text { Surf. }\end{array}$ & $\begin{array}{c}\text { Shower } \\
\text { Head }\end{array}$ & $\begin{array}{c}\text { Suction } \\
\text { Surf. }\end{array}$ & $\begin{array}{c}\text { Pressure } \\
\text { Surf. }\end{array}$ \\
\hline 44103 & 0.00 & 0.572 & 0.236 & - & 0.56 & 0.71 \\
\hline 44108 & 0.00 & 1.093 & 1.122 & - & 0.525 & 0.564 \\
\hline 44308 & 0.00 & 0.946 & 0.953 & - & 0.71 & 0.73 \\
\hline 44135 & 0.20 & 0.634 & 0.426 & 0.745 & 0.558 & 0.668 \\
\hline 44155 & 0.411 & 0.639 & 0.427 & 0.7 & 0.55 & 0.667 \\
\hline 44355 & 0.366 & 0.564 & 0.387 & 0.826 & 0.7 & 0.803 \\
\hline
\end{tabular}


2 ROWS OF HOLES

$35^{\circ}$ ANGLE CHORDWISE

3d SPANWISE SPACING

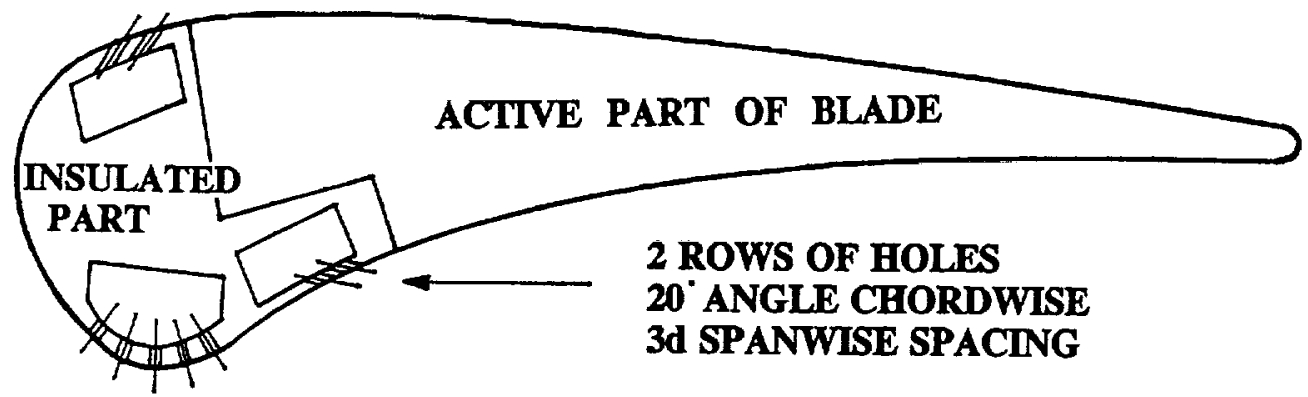

5 ROWS OF STAGGERED HOLES

$45^{\circ}$ ANGLE SPANWISE

7.5d SPANWISE SPACING

HOLE DIA. $\mathrm{d}=0.99 \mathrm{~mm}$

4d ROW SPACING

HOLES NORMAL TO DIRECTION UNSPECIFIED

Fig. 1 C3X vane and cooling hole details.

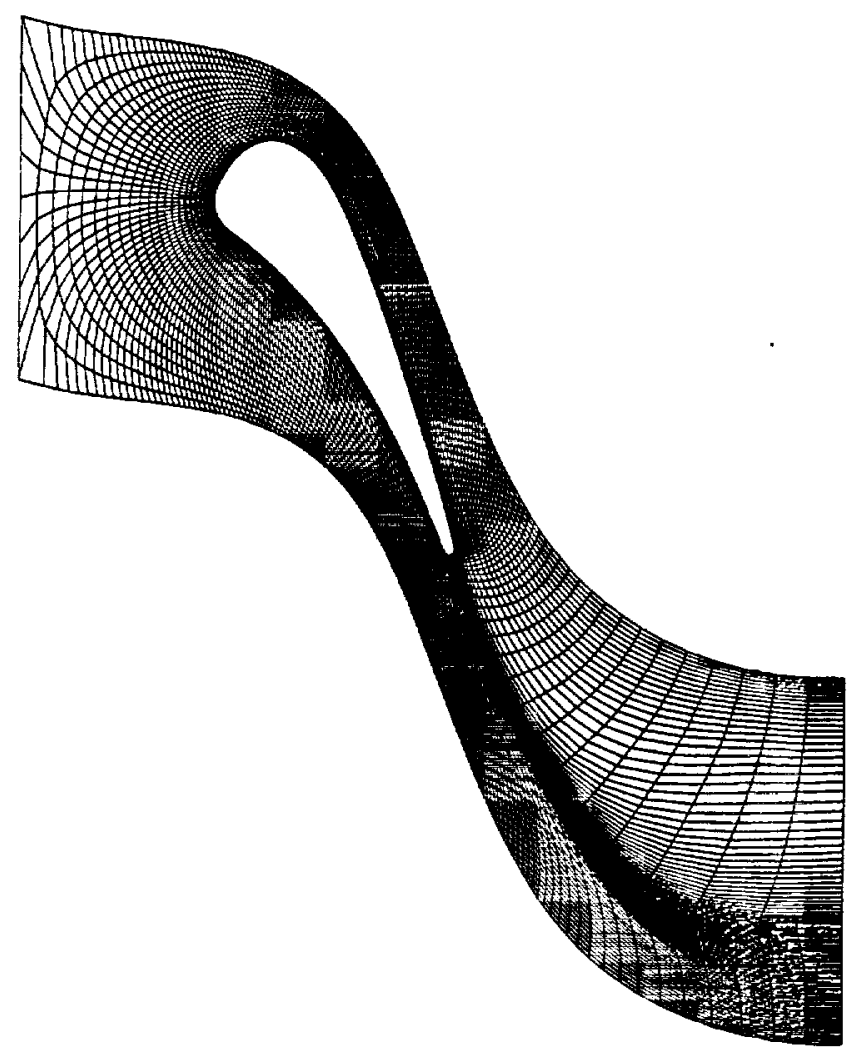

Fig. 2 C-grid over the C3X vane with nine rows of cooling holes. 

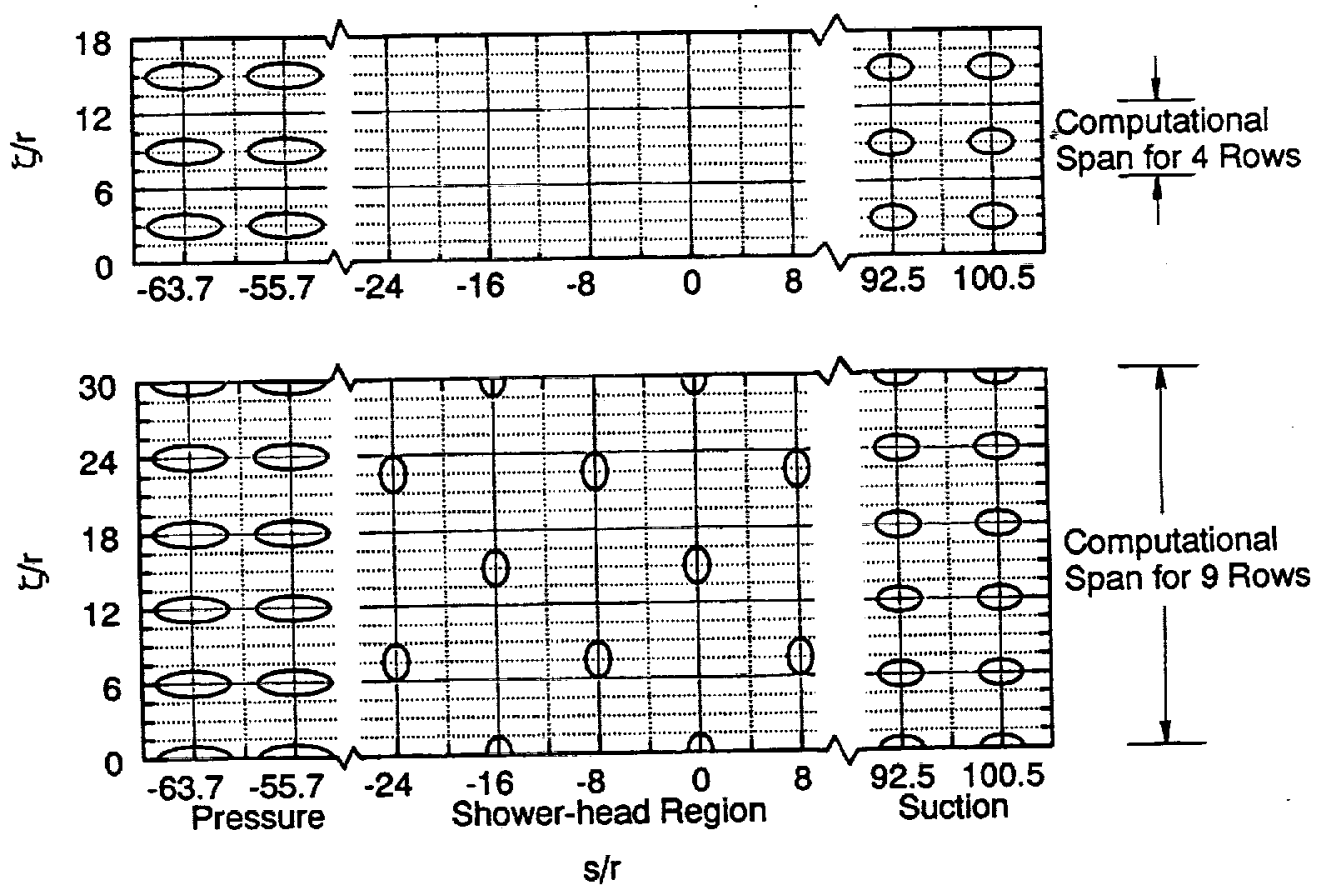

Fig. 3 Computational span for the nine and four rows of holes on the aifoil surface.

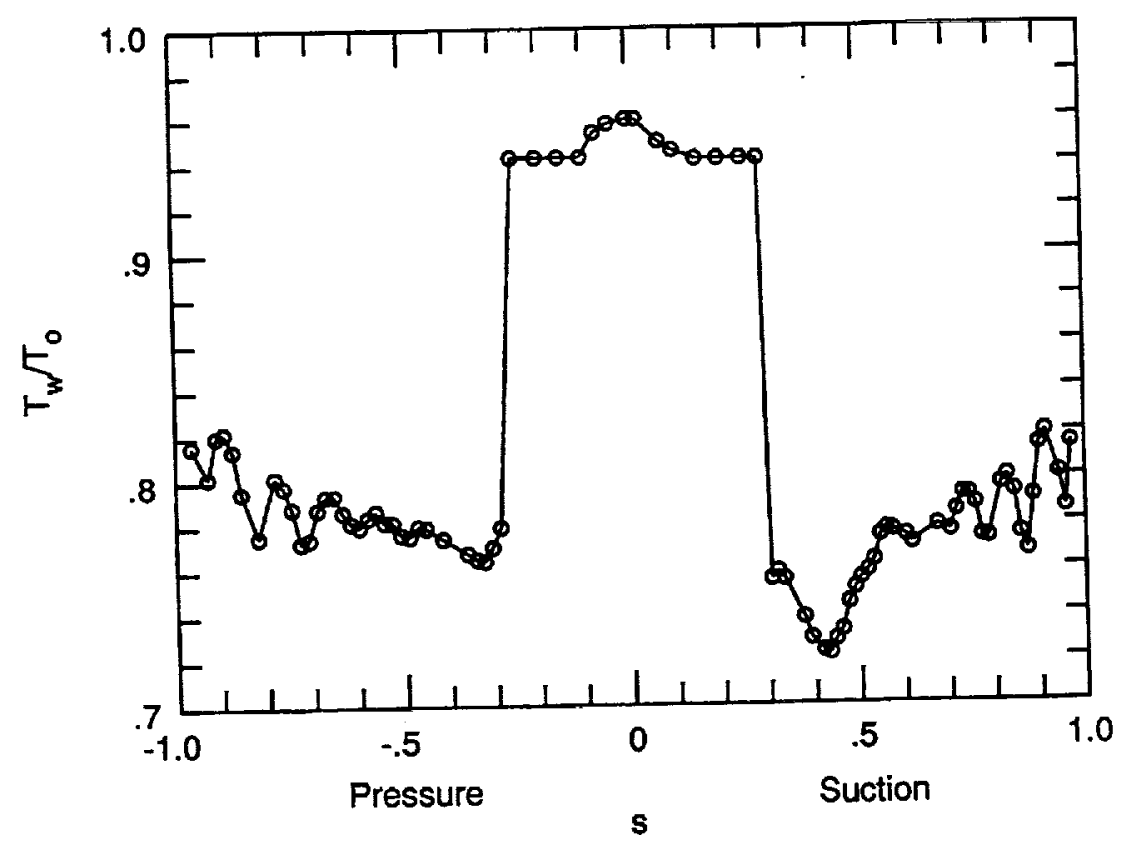

Flg. 4 Airfoil surtace temperature for the Case 44308. 


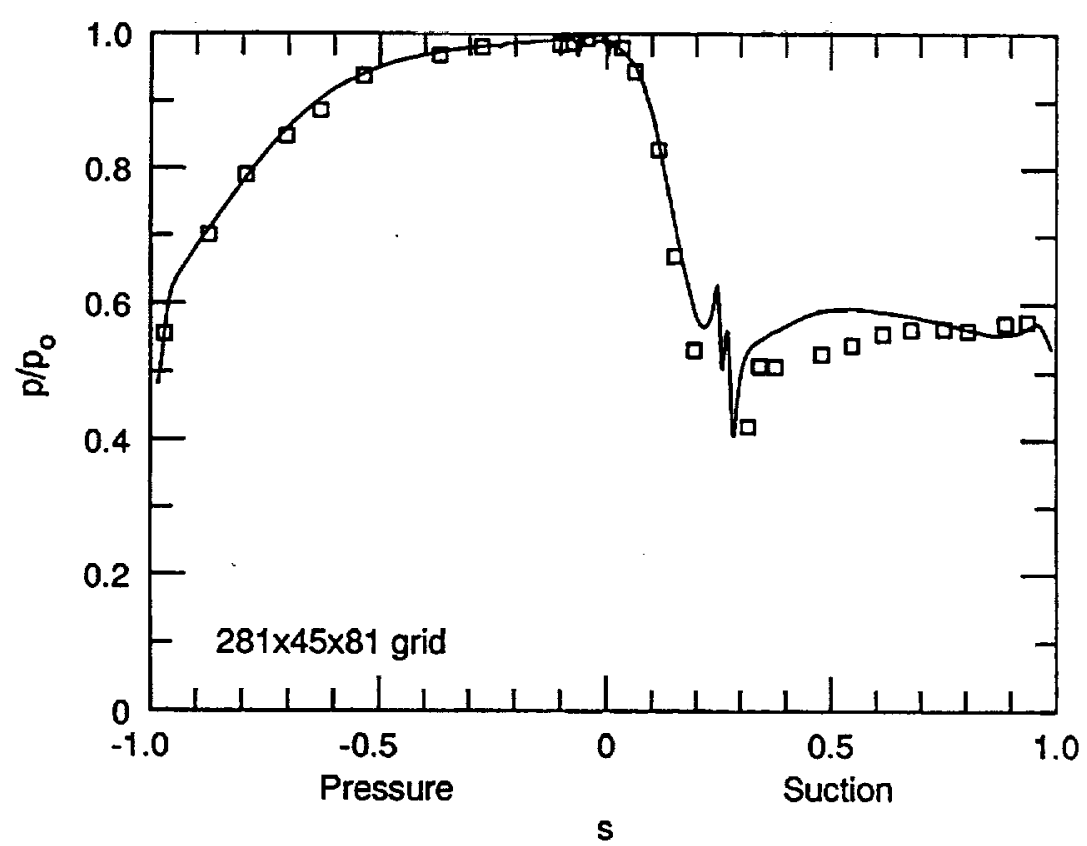

Fig. 5 Static pressure distribution on the airfoil surface (Case 44155). _.. present computation; $\square$, experimental data for uncooled airfoil (Hylton et al., 1988).

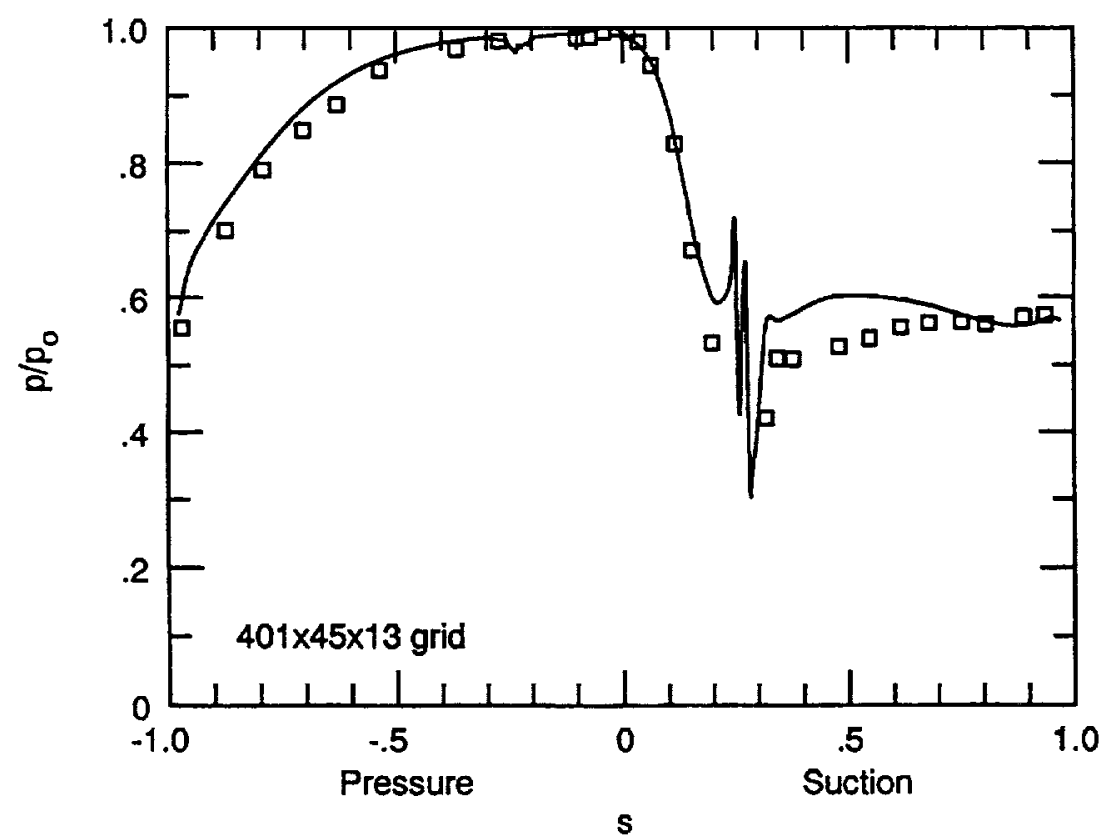

Fig. 6 Static pressure distribution on the airfoil surface (Case 44108). present computation; $\square$, experimental data for uncooled airfoil (Hylton et al., 1988). 


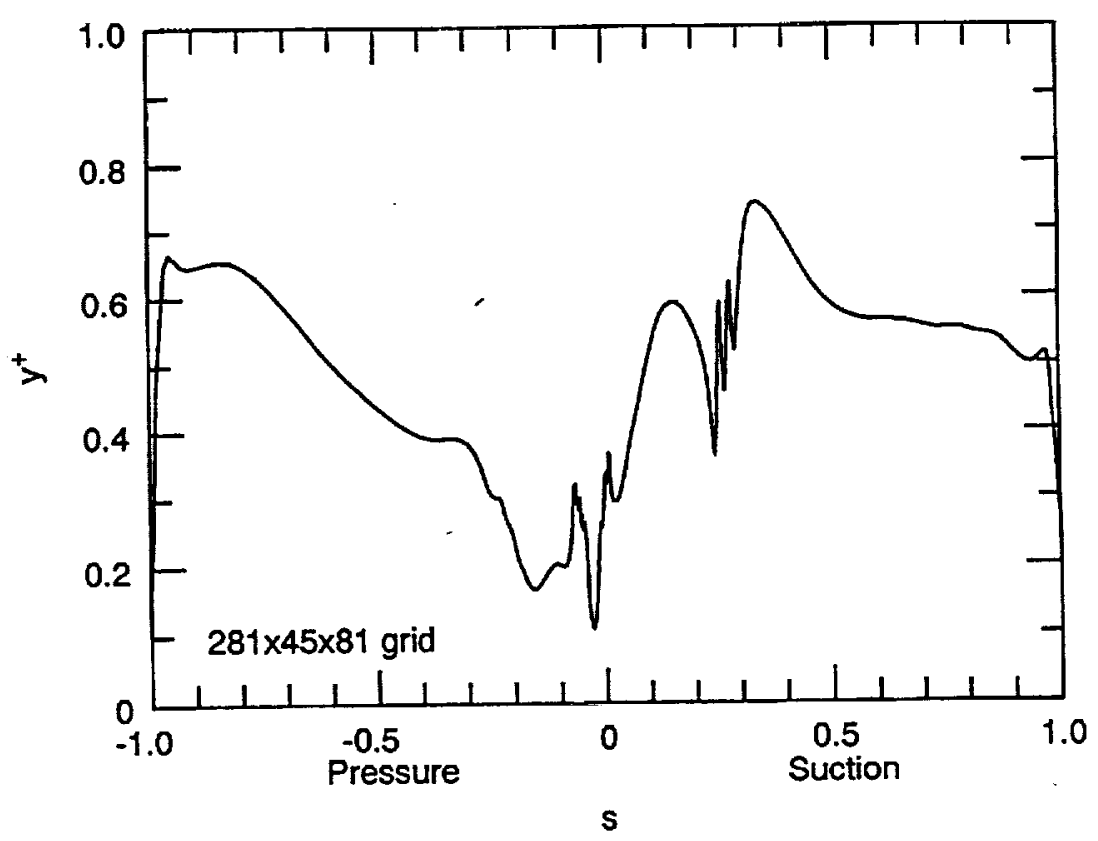

Fig. $7 y^{*}$ of the first point off the airfoil surface for the Case 44155.

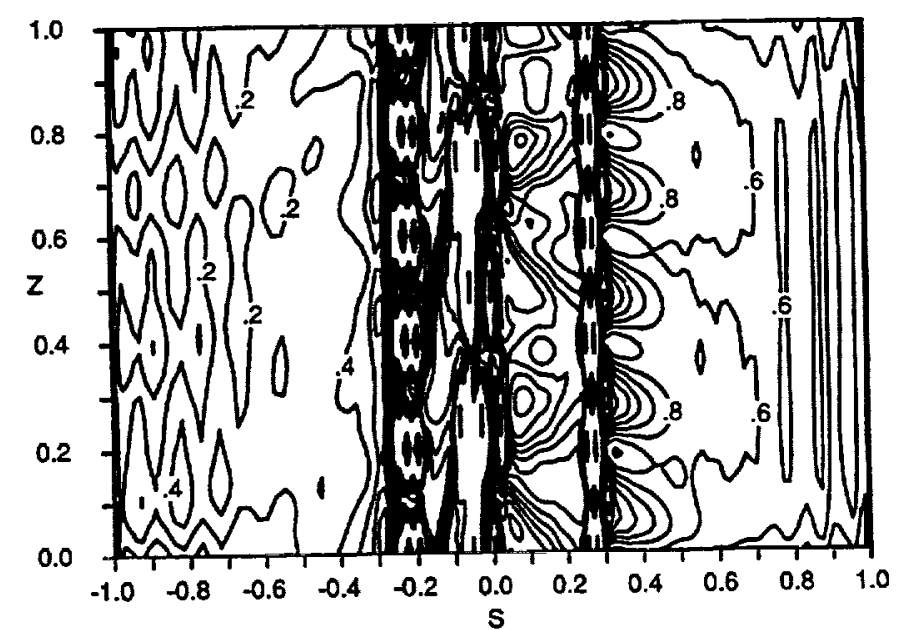

Fig. 8(a) Normalized heat transfer coefficient contours on the airfoil surface for the Case 44155 . 


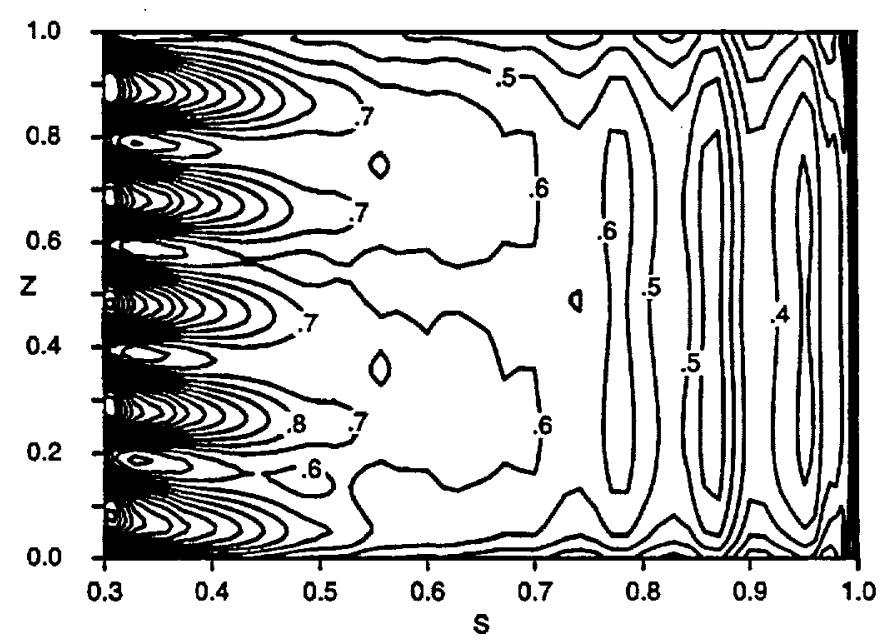

Fig. 8(b) Normalized heat transfer coefficient contours on the suction surface of the airfoil for the Case 44155 .

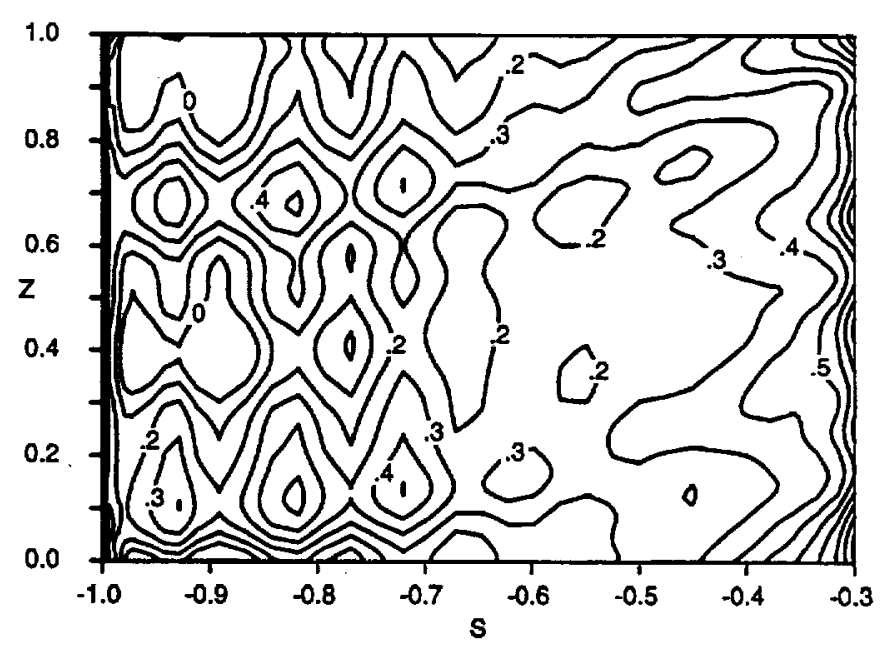

Fig. 8(c) Normalized heat transfer coefficient contours on the pressure surface of the airfoil for the Case $\mathbf{4 4 1 5 5}$. 


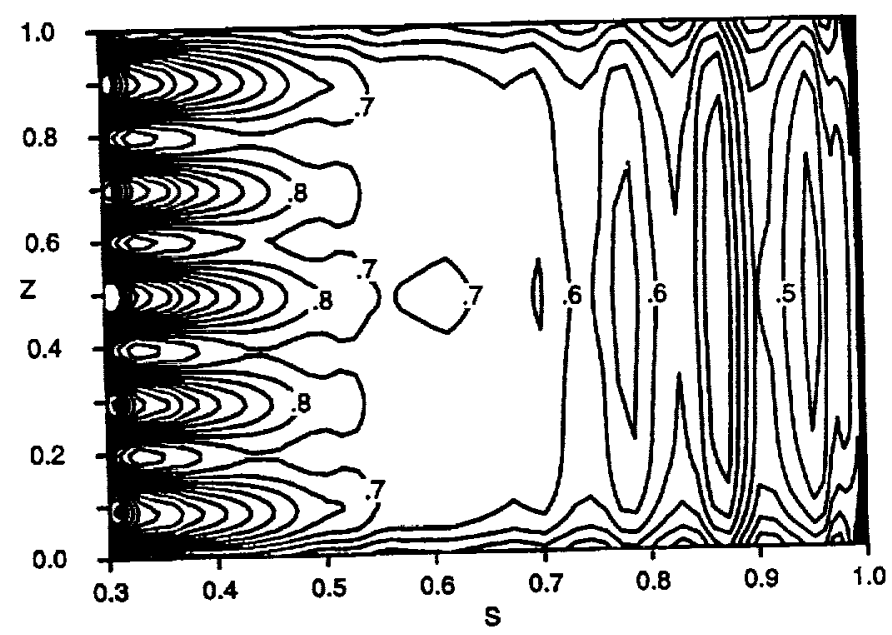

Fig. 9 Normalized heat transfer coefficient contours on the suction surface of the airfoil for the Case $\mathbf{4 4 1 3 5 .}$

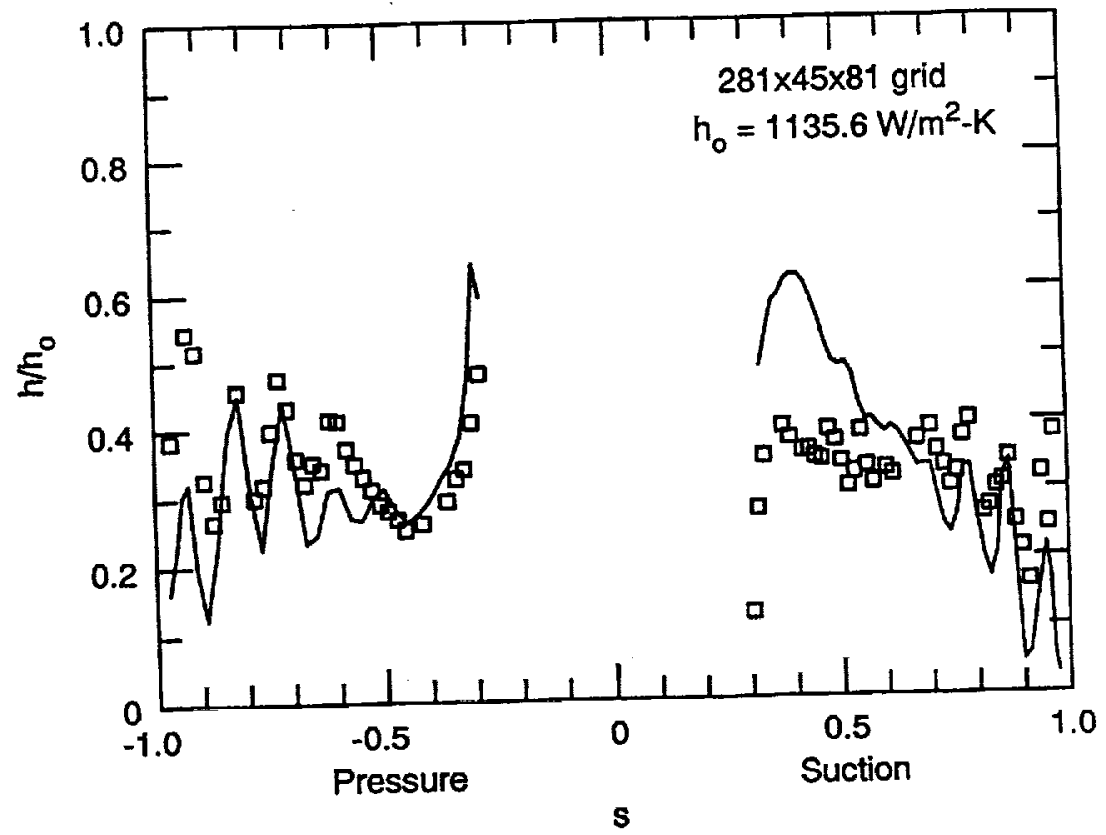

Fig. 10 Normalized heat transfer coefficient on the airfoil surface (Case 44155). present computation; $\square$, experimental data (Hylton et al., 1988). 


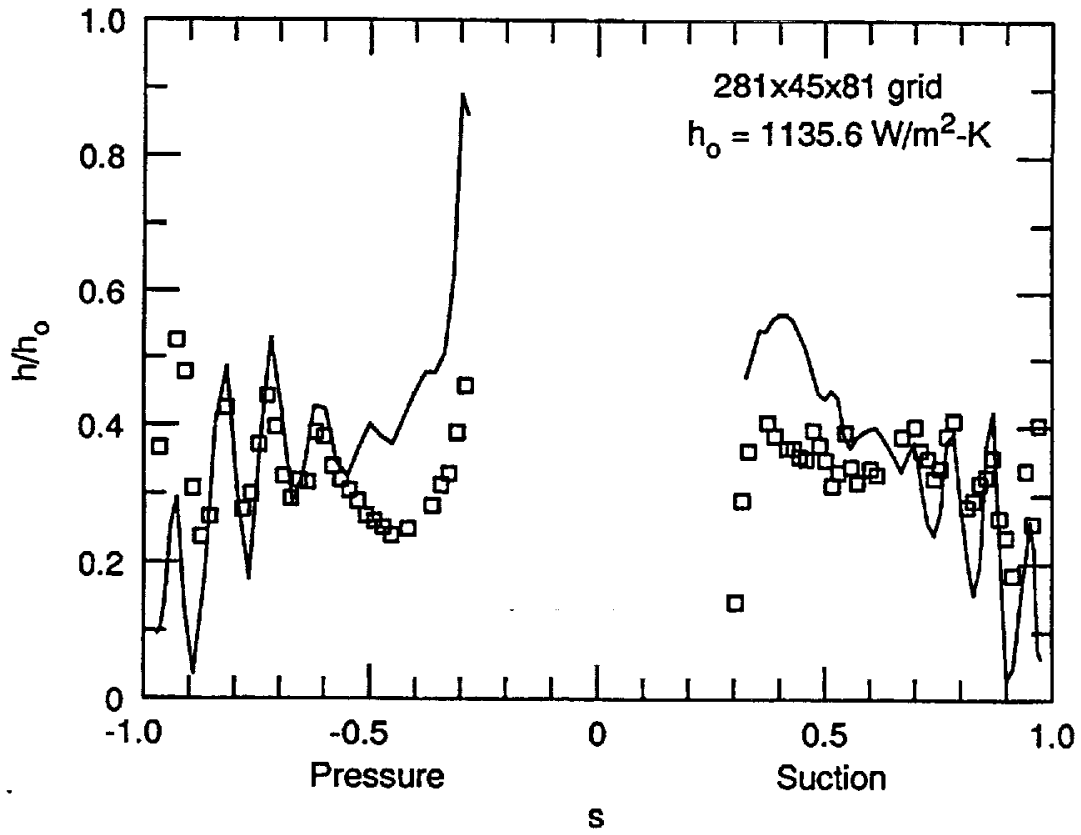

Fig. 11 Normalized heat transfer coefficient on the airfoil surface (Case 44135). present computation; $\square$, experimental data (Hylton et al., 1988).

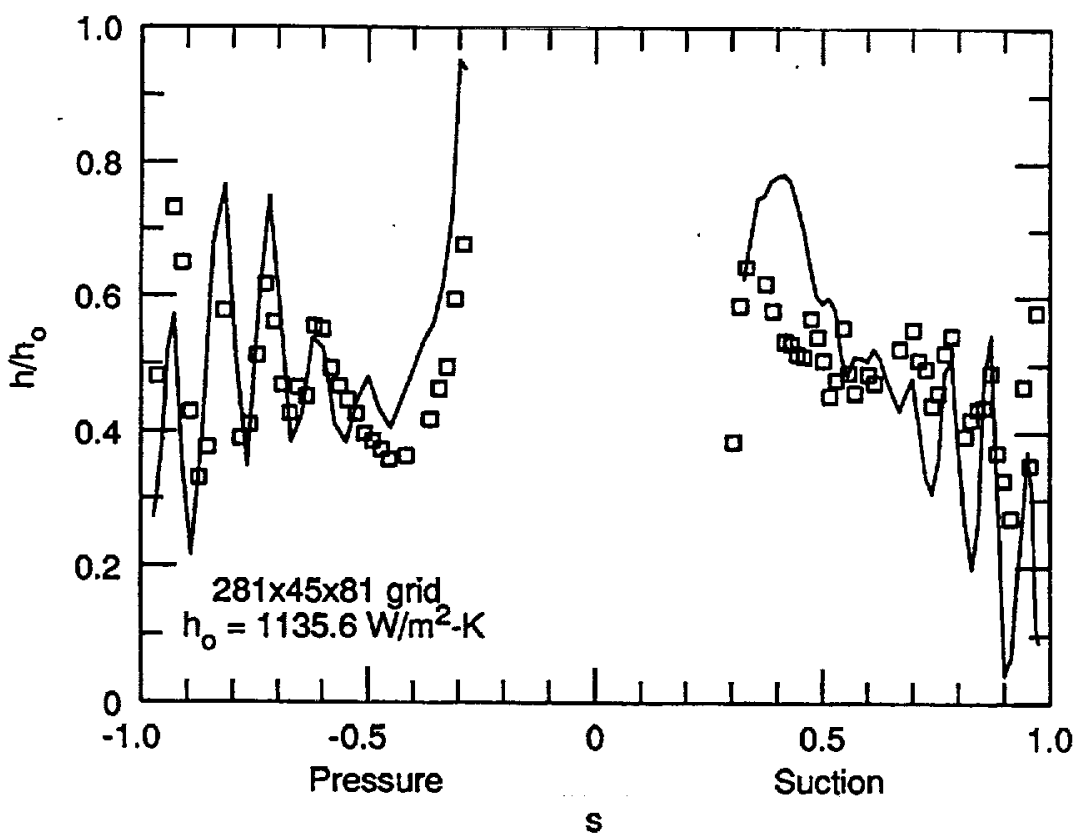

Fig. 12 Normallzed heat transfer coefficient on the airfoil surface (Case 44355). present computation; $\square$, experimental data (Hylton ot al., 1988). 


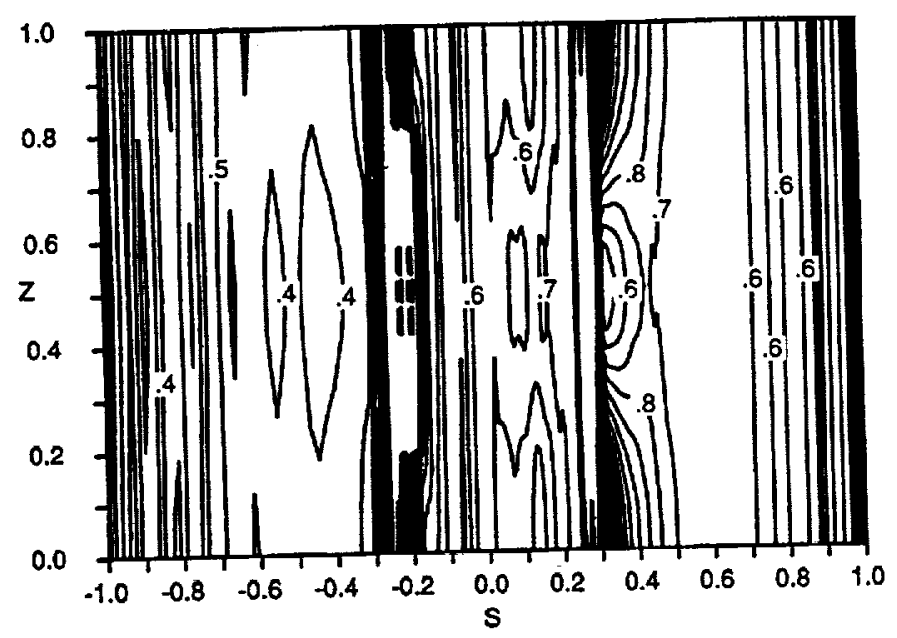

Fig. 13(a) Normalized heat transfer coefficient contours on the airfoil surface for the Case 44103.

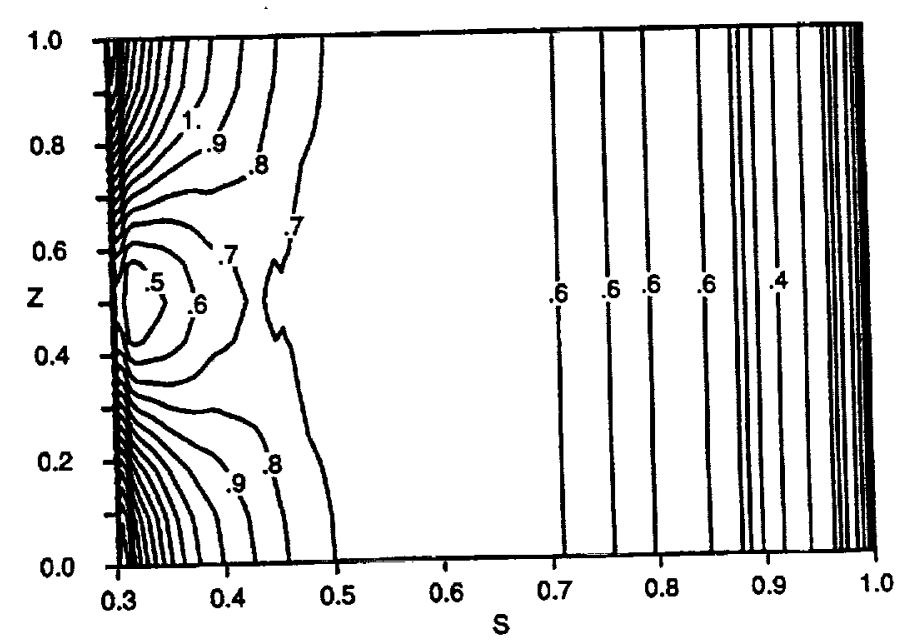

Fig. 13(b) Normalized heat transfer coefficient contours on the suction surface of the airfoil tor the Case 44103. 


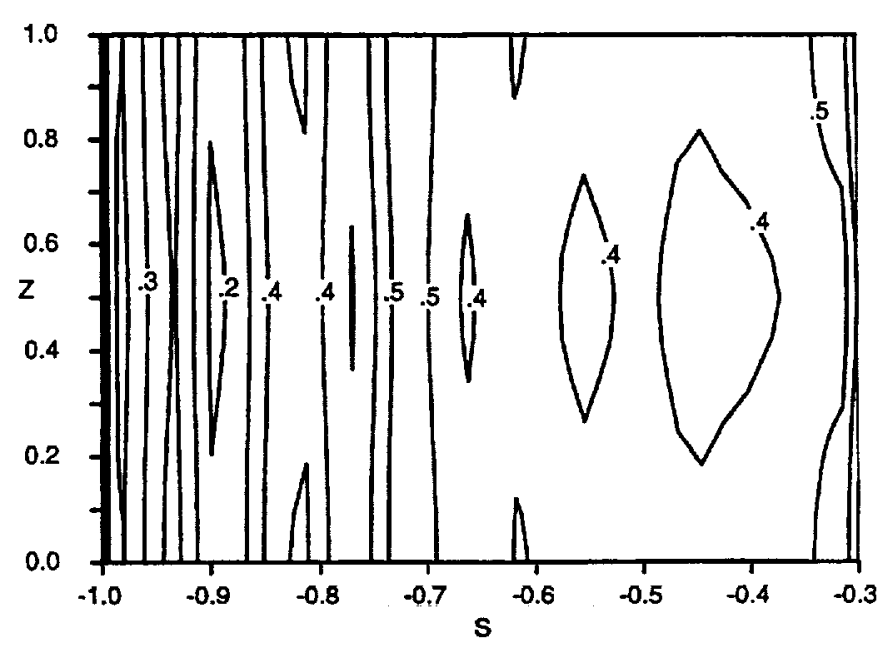

Fig. 13(c) Normalized heat transfer coefficient contours on the pressure surface of the airfoil for the Case 44103.

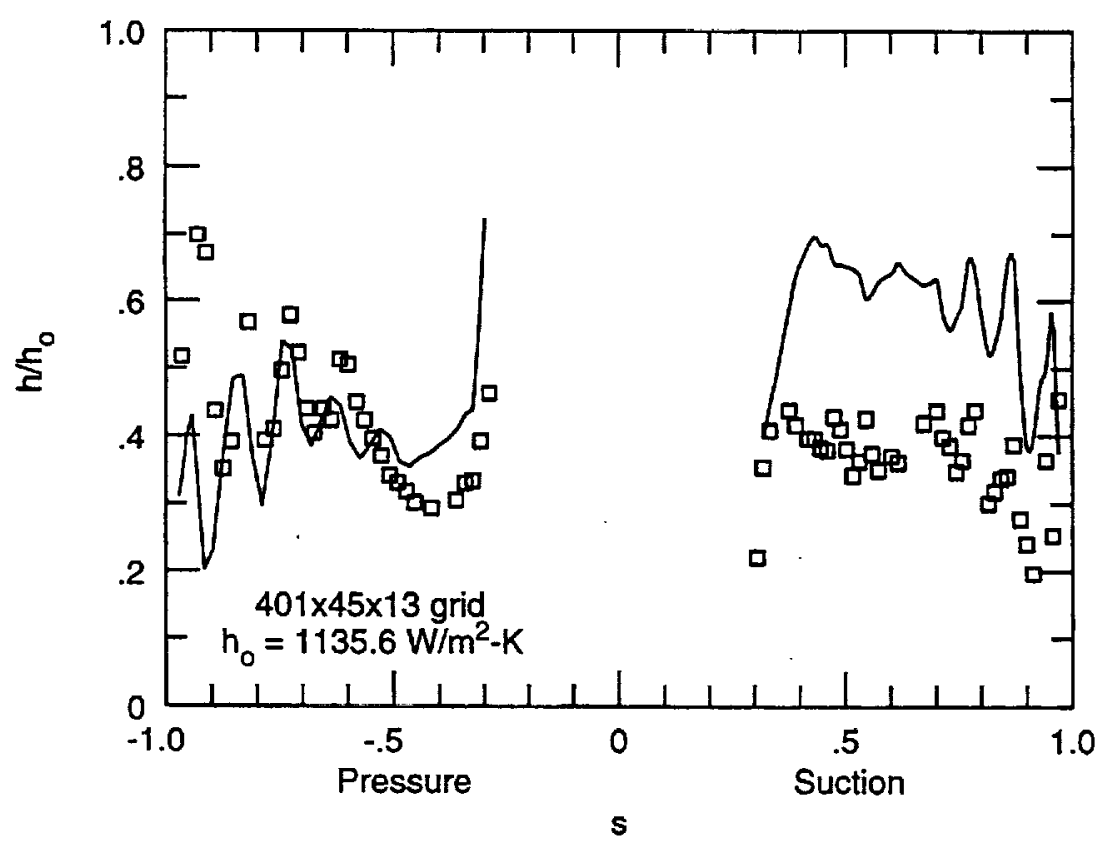

Fig. 14 Normafized heat transfer coefficient on the airfol surface (Case 44103). present computation; $\square$, experimental data (Hytton ot al., 1988). 


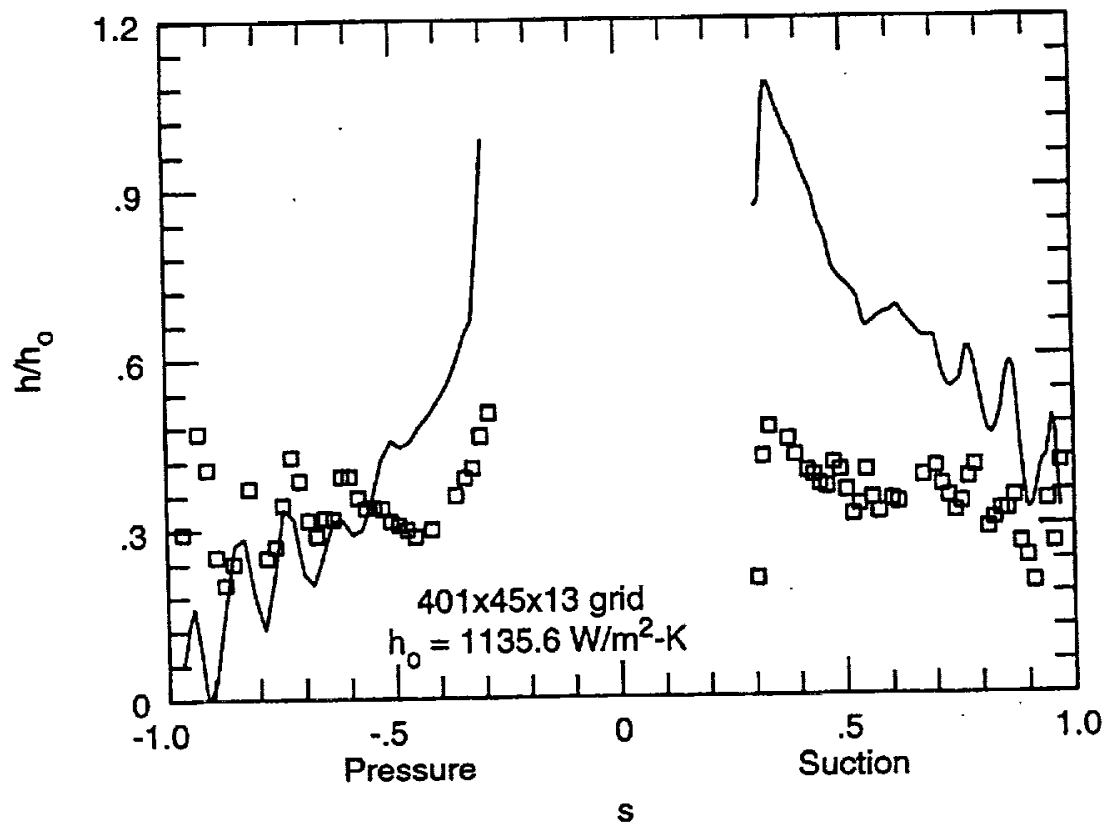

15 Normalized heat transfer coefficient on the airfoil surface (Case 44108). present computation; $\square$, experimental data (Hylton et al., 1988).

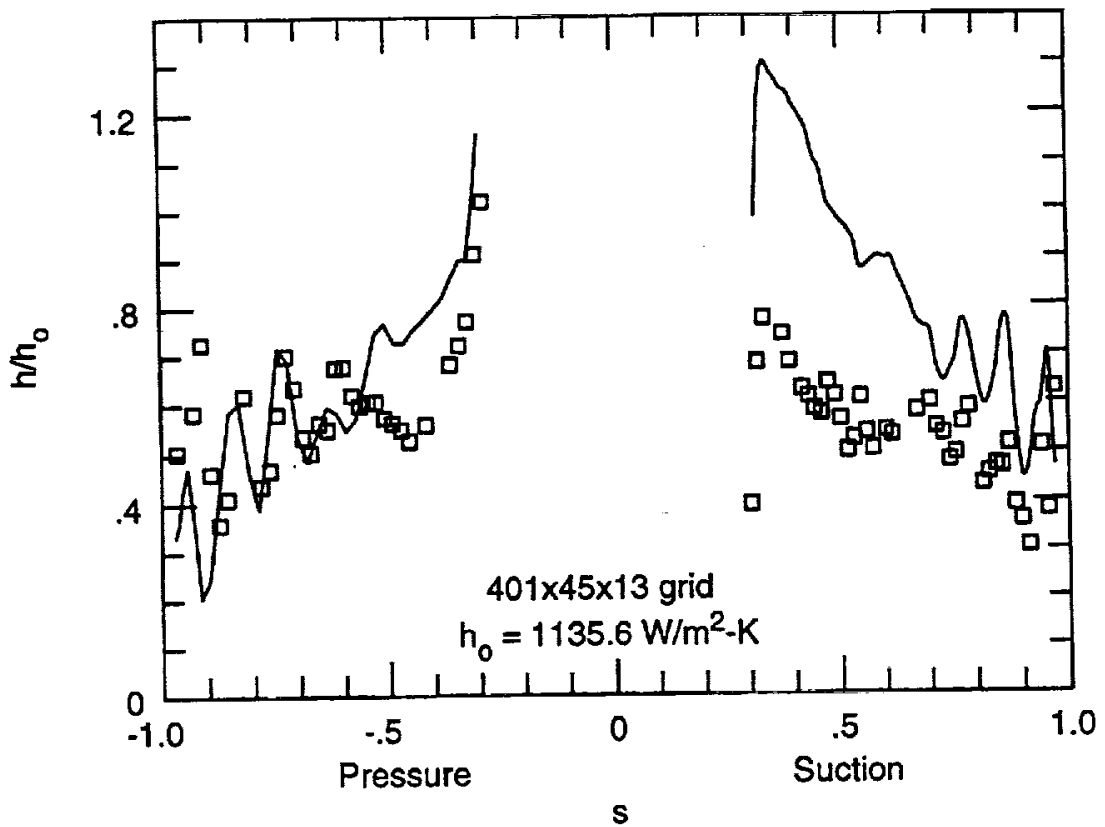

Fig. 16 Normaized heat transler coefficient on the airfol surface (Case 44308). present computation; $\square$, experimental data (Hytton et al., 1988). 


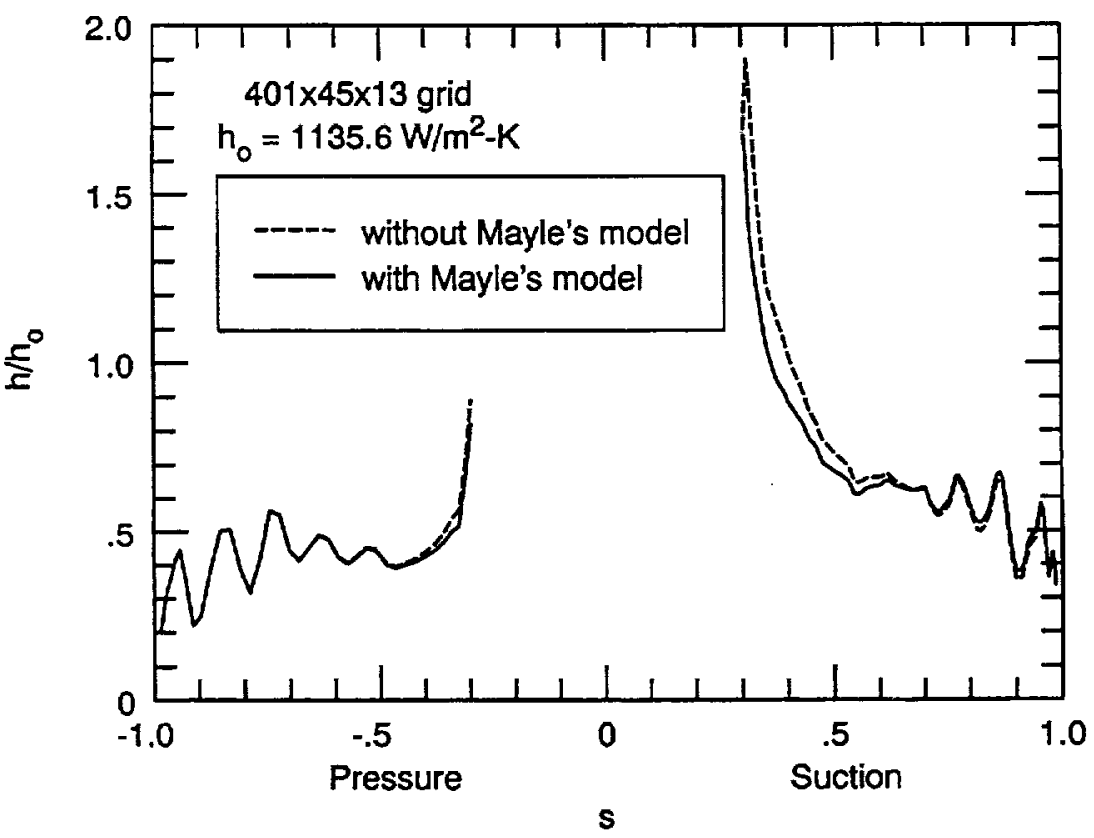

Fig. 17 Eftect of Mayle's transition criterion on the normalized heat transfer coefficient on the airloil surtace (Case 44103). 
Public reporting burden for this collection of information is estimated to average 1 hour per response, including the time for reviewing instructions. searching existing data sources, gathering and maintaining the data needed, and completing and reviewing the collection of information. Send comments regarding this burden estimate or any other aspect of this collection of information, including suggestions for reducing this burden, to Washington Headquarters Services, Directorate for Information Operations and Reports, 1215 Jefferson Davis Highway, Sulte 1204, Arlington. VA 22202-4302, and to the Office of Management and Budget, Paperwork Reduction Project (0704-0188), Washington, DC 20503.

\begin{tabular}{|l|c|c|}
\hline 1. AGENCY USE ONLY (Leave blank) & $\begin{array}{c}\text { 2. REPORT DATE } \\
\text { July } 1994\end{array}$ & $\begin{array}{r}\text { 3. REPORT TYPE AND DATES COVERED } \\
\text { Technical Memorandum }\end{array}$ \\
\hline
\end{tabular}

\section{TITLE AND SUBTITLE}

Prediction of Film Cooling on Gas Turbine Airfoils

6. AUTHOR(S)

Vijay K. Garg and Raymond E. Gaugler

7. PERFORMING ORGANIZATION NAME(S) AND ADDRESS(ES)

National Aeronautics and Space Administration

Lewis Research Center

Cleveland, Ohio 44135-3191

9. SPONSORINGMONITORING AGENCY NAME(S) AND ADDRESS(ES)

National Aeronautics and Space Administration

Washington, D.C. 20546-0001
5. FUNDING NUMBERS

WU-505-62-52
8. PERFoRMING ORGANIZATION REPORT NUMBER

E-8965

11. SUPPLEMENTARY NOTES

Responsible person, Vijay K. Garg, organization code 2600, (216) 433-6788.

12a. DISTRIBUTION/AVAILABILITY STATEMENT

12b. DISTRIBUTION CODE

Unclassified - Unlimited

Subject Category 07

\section{ABSTRACT (Maximum 200 words)}

A three-dimensional Navier-Stokes analysis tool has been developed in order to study the effect of film cooling on the flow and heat transfer characteristics of actual turbine airfoils. An existing code (Arnone et al., 1991) has been modified for the purpose. The code is an explicit, multigrid, cell-centered, finite volume code with an algebraic turbulence model. Eigenvalue scaled artificial dissipation and variable-coefficient implicit residual smoothing are used with a full-multigrid technique. Moreover, Mayle's transition criterion (Mayle, 1991) is used. The effects of film cooling have been incorporated into the code in the form of appropriate boundary conditions at the hole locations on the airfoil surface. Each hole exit is represented by several control volumes, thus providing an ability to study the effect of hole shape on the film-cooling characteristics. Comparison is fair with near mid-span experimental data for four and nine rows of cooling holes, five on the shower head, and two rows each on the pressure and suction surfaces. The computations, however, show a strong spanwise variation of the heat transfer coefficient on the airfoil surface, specially with shower-head cooling.

\section{SUBJECT TERMS}

Film cooling; Heat transfer; Turbine

15. NUMBER OF PAGES

17. SECURITY CLASSIFICATION OF REPORT

Unclassified
18. SECURITY CLASSIFICATION OF THIS PAGE Unclassified
19. SECURTYY CLASSIFICATION OF ABSTRACT Unclassified 